\title{
Dirk van der Hoff: Skeurmaker?
}

\author{
E Oliver \& A D Pont \\ Universiteit van Pretoria
}

\begin{abstract}
Dirk van der Hoff: A schismatic?
\end{abstract}

Dirk van der Hoff, the first minister of the Nederduitsch Hervormde Kerk in the Transvaal is commonly seen as a schismatic and it is said that the consequences of his actions are still felt today in the South African Churches. This article aims to give a very short and synoptic view of the accusations and their tenability.

\section{INLEIDING}

'n Predikant het, omdat hy 'voor zijn geestelijk werk ongeschikt' (Du Plessis 1925:2) was, en daarom geen beroep kon kry nie, 'n toneelspeler geword (Smellekamp 1854). Dat hy 'n totaal oneerbare persoon was, lei geen twyfel nie. 'n Drankverslaafde (Spoelstra 1915:243), vervalser (Scholtz 1956:83) en oproermaker (Smellekamp 1854) by uitnemendheid. Die kerk wat hom uiteindelik, na twaalf jaar, 'n heenkome gebied het, het hy deur sy uitspattige en wanordelike gedrag en onbeheersde heersug (Van Velden 1853) feitlik heeltemal van die evangelie en die betekenis daarvan vervreem. Hierdie man was Dirk van der Hoff: stigter van die Nederduitsch Hervormde Kerk van Afrika (Van der Watt 1977:72 w).

'n Patriot. Kerkman en staatsman. Deur toewyding, opoffering, deursettingsvermoë en leierskap het ds Dirk van der Hoff sy aangenome land en mense vir meer as agt-en-twintig jaar dikwels in ongerief en ongemak gedien en gelei. 'Met Gods Woord het hy op alle lewensterreine sy mense in hulle doen en late begelei, het hy vermaan, aangespoor, moed ingepraat, getroos, geïnspireer en leiding gegee en geneem' (Pont 1974:181). Van hom sê Pelzer (1950:200):

\footnotetext{
- Finansiële ondersteuning van die Raad vir Geesteswetenskaplikc Navorsing in die voorbereiding van hierdie artikel word hiermee erken. Die menings wat in hierdie artikel uitgespreek word en die gevolgtrekkings waartoe gekom word, is dié van die outeur en nie noodwendig dié van die RGN nie. Hierdie is ' $n$ vittreksel uit die skripsie 'Van der Hoff: Liberalis en skeurmaker of gelowige kerkman en -bouer?' wat ingedien en aanvaar is as deel van die vereistes vir die M Div-graad, Fakulteit Teologie (Afd A), Universiteit van Pretoria, onder leiding van prof dr A D Pont.
} 
Ondanks die leemtes wat hom soos enige aardse wese aangekleef het, moet ons erken dat hy beter as enige ander persoon voorbestem was om die geestelike bearbeiding van die hele uitgestrekte boeregemeenskap, man-alleen op sy breë skouers te neem. Slegs 'n persoon met sy werkvermoë kon die las van sy swaar taak oor 'n hele aantal jare dra en al sou hy in die uitoefening van sy taak by meer as een geleentheid tekens van oorprikkelbaarheid openbaar het, dien dit alleen verder ter illustrasie van die besondere eise wat sy werk aan die psigiese weerstand van die kerklike en godsdienstige ampsdraer gestel het. In dieselfde mate moet sy neiging om invloed uit te oefen op ander terreine as die bloot kerklike, aanvaar word as 'n aanduiding van die geweldige omvang van sy geestelike taak in die ongevormde Boeregemeenskap. Ds Van der Hoff het tydens sy ampsbediening nie alleen baanbrekerswerk nie, maar ook beskawingswerk van onskatbare waarde verrig.

Dirk van der Hoff, wat van 1853 tot 1881 predikant in die Transvaalse Republiek was, is een van die mees omstrede figure in die Suid-Afrikaanse kerkgeskiedenis. Vandag nog, meer as 'n honderd jaar na sy dood, kan die blote noem van sy naam reaksie tot gevolg hê. En hierdie reaksie kom gewoonlik uit een van die bogenoemde teenoorstaande pole.

Die vraag ontstaan onwillekeurig na wat daartoe aanleiding kon gee dat twee sulke wyd uiteenlopende sienings vir soveel jare langs mekaar kon bly voortbestaan. Oor die biografiese gegewens betreffende die lewe van ds Van der Hoff bestaan daar nie veel onsekerheid nie, hoewel daar betreklik min histories-betroubare argiefmateriaal aangaande hom bekend is. Pont (1974:165) sê tereg dat die probleme ontstaan wanneer hierdie gegewens geïnterpreteer word.

Lees 'n mens die verskillende verwysings na en beskrywings van die lewe en werk van ds Van der Hoff, word dit gou duidelik dat die aanklagte wat deur die Spoelstra-skool (Spoelstra 1915; Du Plessis 1925; Scholtz 1956; Van der Watt 1977) teen hom ingebring word, hoofsaaklik in twee kategorieë uiteenval. Aan die een kant word hy daarvan beskuldig dat hy 'n liberalis is, wat hierdie teologie so diep in die Hervormde Kerk ingedra het, dat die oorblyfsels daarvan vandag nog deel uitmaak van hierdie kerk se teologie. Aan die ander kant word hy by voorkeur gesien as 'n schismaticus. Van der Hoff word verantwoordelik gehou vir die sogenaamde afskeiding van die Transvaalse kerk van die Kaapse kerk. Hy, en hy allén, was ook die oorsaak van die kerkskeurings in Transvaal. 
Met hierdie oorsigartikel word verkennend na die bestaande, gepubliseerde materiaal omtrent die werk en lewe van Dirk van der Hoff gekyk. Slegs één aspek uit die beskikbare stof geniet aandag, naamlik die kontrovers rondom die figuur van Van der Hoff as skeurmaker in die kerk. Hierdie aantygings, die agtergrond waarteen die gebeure gesien moet word en die houdbaarheid van hierdie tipering word oorsigtelik ondersoek en geëvalueer.

\section{WIE WAS DIRK VAN DER HOFF?}

Die Nederlander Dirk van der Hoff is op 2 September 1814 te Dordrecht gebore. Hy was die seun van Pieter van der Hoff en Jacoba Botbijl. Nadat hy sy skoolloopbaan, wat volledig in Latyn aangebied is, voltooi het, is hy in 1833 na Leiden om hom in die teologie te bekwaam. In Mei 1840, nadat hy die proponentseksamen geslaag het, word hy beroepbaar gestel. Veel meer as dit is nie oor sy ouerhuis en jeugjare bekend nie.

Op daardie stadium was daar 'n oorvloed van predikante in die Nederlandse Hervormde Kerk en moes Van der Hoff saam met ander wag op 'n beroep. Manne soos Ham, Stucki, Begemann en Van Warmelo het ook nie gou beroepe gekry nie en hulle daarom later in Suid-Afrika kom vestig (Erasmus 1950:37). Terwyl Van der Hoff op 'n beroep gewag het, het hy onder meer by die bekende boekhandel van Frederik Muller te Amsterdam gewerk. Hy is getroud met AM van Otterloo. Prof UG Lauts, 'n pleitbesorger vir die belange van die Trekkers (Ploeger 1952), oortuig Van der Hoff op 1 Julie 1852 om 'n beroep na die Transvaal te aanvaar.

Die egpaar vertrek per skip na Kaapstad waar hulle op 5 November 1852 aanland. Van der Hoff het dadelik sy dokumente aan ds A Faure, aktuaris van die Kaapse kerk, voorgele en is so as predikant van die kerk gelegitimeer. Vyf maande later het hulle na Natal vertrek om vandaar die reis na Transvaal oor land voort te sit. Op 27 Mei 1853 kom hulle eindelik in Potchefstroom aan. Ses jaar lank was ds Van der Hoff die enigste predikant in die Transvaal en hy bedien die Potchefstroomse gemeente tot sy dood op 9 Oktober 1881 .

\section{TOESTANDE IN TRANSVAAL}

Die jare wat Dirk van der Hoff predikant in Transvaal was, was moeilike vormingsjare op sosiale, kerklike en staatkundige gebied. Dit was die tyd waarin 'n nuwe vaderland sy beslag gekry het. Die groeipyne, stryd en onenigheid wat met sulke ontwikkelings gepaard gaan, het dan ook nie uitgebly nie. 
Reeds tydens die Groot Trek het hierdie worsteling begin, toe daar skynbaar net oor één ding eenstemmigheid was, naamlik die strewe na 'n 'vrye, onafhanklike vaderland' (Storm 1989a:682). Oor byna alle ander sake het spanning geheers (Oberholzer 1989:675). Dit is dus ondenkbaar dat alle probleme in die vroeë vyftigerjare, kort na die totstandkoming van die Voortrekkerrepubliek in Transvaal, uitgestryk sou wees.

Die feit dat Van der Hoff nie altyd bewus was van die onderliggende struwelinge, partyskappe en vooroordele nie, het hom dikwels duur te staan gekom. Pelzer (1950:61) stel dit so: 'Heel dikwels was onkunde, ongeletterdheid of die onvermoë om 'n bedoeling reg te begryp, vir die oorgevoeligheid verantwoordelik.'

Duvenage (1966:6) stel dat die gebrek aan intellektuele ontwikkeling daartoe gelei het dat die Afrikaner-pioniers hulle menseregte persoonlik gehandhaaf het, eerder as om dit aan 'n owerheid op te dra. Daarom is probleme eerder emosioneel as rasioneel benader. Bevordering en beveiliging van persoonlike belange het baie swaarder geweeg as die algemene volks- of staatsbelange.

'Hoewel bedeel met voldoende gesonde verstand, vlugheid van begrip en 'n verbasende veelsydigheid wat die alledaagse handvaardighede en praktiese bedrewenhede aanbetref, het die Oorvaalse Emigrante geestelik nog in die sewentiende-eeuse toestande verkeer toe hulle aan negentiende-eeuse intellektuele standaarde moes beantwoord' (Duvenage 1966:5).

Ook die leiers was produkte van hulle tyd en omgewing. Hulle was hoofsaaklik aangewese op 'gesonde verstand waarvan almal nie ewe veel ontvang het nie' (Duvenage 1966:9). Die feit dat die leiersfiguur so 'n belangrike rol in die vestigingsgeskiedenis in die Oorvaalse speel, bring mee dat daar min of meer drie regionaal-politieke groeperinge in die Oorvaalse ontstaan: In die noorde was die Potgieter-groep wat staatkundig gesproke, die leierbeginsel voorop gestel het. Die Lydenburgse groep onder leiding van JJ Burgers het 'n oordrewe demokrasie nagestreef. Die westelike Pretorius-party het 'n demokrasie met 'n sterk uitvoerende gesag verlang. Tussen die drie groepe was daar meer male spanning en stryd. Veral die deurtastende optrede van Pretorius met die ondertekening van die Sandriviertraktaat het Wes-en Oos-Transvaal van mekaar vervreem.

Van der Hoff vestig hom in Potchefstroom en laat hom deur Pretorius lei in sy eerste optrede (Engelbrecht 1936:79). Dit verbind hom onherroeplik aan die WesTransvaalse regionaal-politieke groep. Dít word beklemtoon deur sy aanvaarding van die beslissing van die Algemene Kerkvergadering van 1853 om die inlywing van die Transvaalse gemeentes by die Kaapse kerk te verwerp. 


\section{DIE INLYWING BY DIE KAAPSE KERK}

Scholtz (1956:83) stel dat Van der Hoff daarvoor verantwoordelik was dat die 'kerklike eenheid van die volk verbreek' is. Hy meen dat Van der Hoff gekant was teen die inlywing en dat hy 'n Algemene Kerkvergadering laat hou het waar hy politieke onafhanklikheid as hoofmotief vir die afstem van inlywing gegee het. J P Jooste (1871:2) het ds Van der Hoff daarvan beskuldig dat hy die Transvalers afvallig gemaak het van die Kaapse kerk.

Die geskiedenis toon baie duidelik dat die Voortrekkerkerk nie deel van die Kaapse kerk was nie en daarom ook nie van die Kaapse kerk kon afskei of skeur nie. Die Voortrekkerkerk was 'n selfstandige voortsetting van die kerk waarin die Voortrekkers in die Kaapkolonie gebore is en grootgeword het. Die Algemeen Reglement van 1824 bepaal in artikel 20 dat die fisiese grense van die kerk en die grense van die Engelse kolonie saamval. Die kerk het feitlik as staatskerk gefunksioneer (Jooste 1946:145). Die Voortrekkers het die Kaap verlaat met die uitsluitlike doel om hulleself van die Engelse bewind en kolonie los te maak en dit het vanselfsprekend die kerk in die Kaapkolonie ingesluit.

Die Kaapse kerk het tydens die sinode van 1837 sy standpunt ten opsigte van die Groot Trek in 'n Herderlijken Brief gestel (Pont s a:91-103). Dit het meegebring dat die ring van Graaff-Reinet die Voortrekkers nie meer as lidmate van die kerk beskou het nie. Hierdie brief, die gesindheid waarin dit opgestel is en dit wat daaruit voortgespruit het, was seker die grootste enkele faktor wat meegebring het dat daar ' $n$ aansienlike afstand tussen die kerk in die Kaap en die Trekkers ontstaan het (Pont 1986:155). Die Voortrekkerkerk kon nie 'n voortsetting van die kerk in die Kaap wees nie, want dit kom tot stand deur die toedoen van die Voortrekkerowerheid en, interessant genoeg, was die eerste predikante, Smit en Lindley, nie predikante of lidmate van die Kaapse kerk nie (Pont 1989:661-663). Die pad wat hierdie kerk geloop het was nie altyd maklik nie. Die Voortrekkerkerk, waarin al die Voortrekkers opgeneem is, is deur politieke verwikkelinge geknou. Met die anneksasie van die Natalse deel van die Voortrekkerrepubliek in 1843 en die Oranjeriviergebied in 1848 , het net die Oorvaalse gemeentes selfstandig voortbestaan (Pont 1989:665-667), maar sonder 'n predikant want Lindley het al in 1847 sy bediening onder die Voortrekkers neergelê. Dit gee aanleiding tot die ontstaan van 'n merkwaardige situasie: Aan die een kant is gevrees dat noue skakeling met die Kaapse kerk tot anneksasie kon lei en aan die ander kant het die behoefte aan kerklike bediening noue skakeling met die Kaapse kerk genoodsaak (Pont 1989: 666). Vir die Transvaalse gemeentes was die verkryging van 'n eie predikant die hoogste prioriteit, maar die Kaapse predikante wouøeers die Transvaalse gemeentes by die Kaapse kerk inlyf voordat die saak van 'n eie predikant aandag sou kry. 
Gesien in die lig van die bepaling van 1824 is dit vreemd dat die Kaapse predikante van mening was dat dit moontlik sou wees om gemeentes buite die grense van die Kaap by die 'staatskerk' van die kolonie in te lyf.

Na die ondertekening van die Sandrivierkonvensie in 1852 waarin die onafhanklikheid van die Transvaal deur Engeland erken is, maak di A Murray en J H Neethling, tydens 'n besoek aan Transvaal, 'n vreemde, onuitvoerbare voorstel. Hulle stel dat 'n predikant na die Transvaal sou kom indien die gemeentes èn die Volksraad inlywing by die Kaapse kerk sou aanvaar. Hierdie aanbod word in Oktober 1852 deur die sinode van die Kaapse kerk in gewysigde vorm bekragtig. Die eerste Algemene Kerkvergadering van die Transvaalse gemeentes, wat in Augustus 1853 plaasgevind het, verwerp hierdie voorstel enersyds omdat ds Van der Hoff in Mei 1853 in Potchefstroom aangekom en die behoefte aan hulp van die Kaapse kerk verval het, en andersyds omdat dit bekend geword het dat ds Andrew Murray by Sandrivier die onafhanklikheidserkenning deur Engeland teengestaan het en ook standpunt ingeneem het teen die onafhanklikheid van die Vrystaat (Spoelstra 1963:108). Die Transvalers het gevoel dat die ultimatum 'of onder de Synode of zonder Leeraars' (Engelbrecht 1952b:140) van hulle afgepers is.

Die vraag ontstaan of ds Van der Hoff vir die verwerping van die inlywing verantwoordelik was of nie. Hy is onder andere deur A W J Pretorius self gevra dat hy moet toesien dat die kerk nie onder die Kaapse sinode gestel moet word nie. Pretorius en talle burgers was bang vir gelykstelling en die 'geestelijke zwaard' waarmee Sir Harry Smith hulle gedreig het (Van Warmelo 1881:174). Gevolglik is 'n gesamentlike vergadering van die Krygsraad, Volksraad en Algemene Kerkvergadering te Potchefstroom gehou. Tydens hierdie vergadering, gehou op 22 November 1853 word besluit om nie die inlywing goed te keur nie. Ds Van der Hoff was aanvanklik egter ten gunste van inlywing:

Zijn Eerw. geeft den wensch te kenne dat de gemeente alhier onder de K. Sijnode mogten ingelijfd worden. Hy stelt der vergadering het voordeelige en wenschlijke dier zaak voor en waarschuwt ernstig voor de nadelige gevolgen die uit eene weigering der inlijving kunnen voortvloeijen. De geheele vergadering is echter van een geheel ander gevoelen. Haar hoofdleuse is: burgerlijk vrij en onafhankelijk, wenschen wij dit ook in het kerkelijke. Wij wenschen onze eigene kerkelijke zaken zelf te besturen, en in deze niet ondergeschikt te zijn aan de Kaapsche Sijnode. De Koning der Kerk Jesus Christus onze Heer, zij ons eenige hoofd. Deze en dergelijke andere uitdrukkingen door krachtige drangredenen, te veel om hier te vermelden, onder- 
steund, deed den Leeraar eindelijk ook besluiten zijne toestemming te geven aan den algemeene wensch des Kerkeraads, die volgens het zeggen der kerkraadsleden, ook de algemeen wensch van het publiek was.

(AKV 1853:3,4)

So het Van der Hoff doelbewus vir die Voortrekker-ideaal gekies en ywerig daarvoor begin werk (Oberholzer 1989:673). Scholtz (1956) stel dat Van der Hoff reeds voor sy aankoms in Suid-Afrika afkerig gestaan het teenoor die Kaapse kerk (Scholtz 1956:77) as gevolg van indoktrinasie deur prof Lauts. Die optrede van Van der Hoff bewys hierdie afleiding egter as geforseerd.

Van der Hoff se omstandighede, waar hy as vreemdeling in 'n komplekse situasie instap, maak dat hy die leiding en opvattings wat hy ontmoet, aanvaar en daarby aanpas. Die feit dat A W J Pretorius en van sy invloedrykste kerkraadslede standpunt inneem téén die inlywing, dwing Van der Hoff in hierdie rigting. Tog meen hy om tydens die Algemene Kerkvergadering die inlywing aan te beveel - 'n bewys dat hy beide kante van die saak wil beklemtoon. Die gevoel téén die inlywing noop Van der Hoff om sy gemeente en gemeenskap se wens te eerbiedig. Dit is opvallend dat die Oos-Transvaalse gemeenskap in Augustus wel die inlywing verwerp het maar tog daaroor kriewelrig gebly het terwyl 'n groep in Wes-Transvaal dit nie aanvaar het nie (Scholtz 1956:91).

Dit wil dus voorkom asof Van der Hoff se koms na Transvaal, juis op 'n kritieke tydstip in die geskiedenis, deur sommige historici misbruik word om sodoende 'n 'kerkskeuring' in die geskiedenis 'in te skryf. Van der Hoff word 'n sondebok gemaak terwyl die kompleksiteit van die situasie, die spanning tussen die regionaalpolitieke groepe in Transvaal en die duidelike standpunt van die kerkvolk onderskat word (kyk veral Spoelstra 1982:152-155).

\section{VAN DER HOFF EN DIE LYDENBURGERS}

Erasmus Smit het saam met die Retieftrek na Natal gegaan en op die reis is hy as predikant deur die Trekkers aangestel (Storm 1989b:44 vv). Ten spyte van die feit dat hy nie 'n geordende predikant was nie, was hy wyd belese en teologies goed onderlê (Pont 1986:175). Hy was 'n voorstander van die Calvinistiese teokratiese ideaal en nasionale volkskerk. Hiervoor vind hy steun by à Brakel, die skrywer van die populêre dogmatiekhandboek van die Trekkers. Smit is egter nie algemeen deur die Trekkers aanvaar nie. Die teenkanting het veral van sy swaer Maritz se 
mense gekom waar Sarel Cilliers groot aansien geniet het. Hierdie groep was meer patrioties gesind (Beyers 1967:285 w) met 'n groot waardering vir die demokrasie. Aansluitend hierby het hulle die vryekerkgedagte gesteun.

Later sluit die Maritz/Cilliers-volgelinge merendeels by J J Burger aan met sy oordrewe demokratiese opvattings. Na die anneksasie van Natal het hierdie groep, wat grotendeels na Lydenburg se wêreld verhuis het, groot invloed daar begin uitoefen. Dit was onder invloed van hierdie Trekkers uit Natal dat daar op 1 Augustus 1845 'n Volksraad in Transvaal gestig is, wat gesien is as 'n voortsetting van die vroeëre Pietermaritzburgse Volksraad. Hierdeur het die leierskap van Potgieter in gedrang gekom, en as gevolg daarvan ontstaan twee partye. Erasmus (1950:8) stel: 'Hierdie Burger-party het later die Lydenburgse party geword waarvan H T Bührmann die aanvoerder was. Dit was die oorsaak van latere staatkundige en kerklike moeilikhede. Pretorius en Potgieter het glad nie so baie van mekaar verskil nie. Dieselfde geld van hulle opvolgers. Dit was gewoonlik Bührmann wat die aanstoker was.'

Die saad van verdeeldheid (kerklik en staatkundig) was reeds vanaf die Groot Trek aanwesig. Dit lei tot die ontstaan van die verskillende regionaal-politieke groepe in Transvaal, met nog verdere nuansering binne die partye (Spoelstra 1982: 153).

Die Lydenburgse probleem, op kerklike vlak, ontstaan wanneer ds Van der Hoff in 1853 in Transvaal aankom en sonder meer deel word en as 'kerklike woordvoerder' van die Wes-Transvaalse regionaal-politieke groep gesien word. Spoelstra (1982:153) tipeer die Lydenburgers soos volg: 'Die volksraadgesinde Lydenburg en Potgietermense te Zoutpansberg was krities en selfs vyandig teenoor Pretorius, staatkundig nog los en het inlywing by die Kaapse sinode of hulp van Smellekamp uit Nederland verwag om 'n eie predikant te bekom....'

Dit was dus, indien die beskikbare materiaal sorgvuldig nagegaan word (Duvenage 1966) duidelik dat die bestaande antitese Wes-Transvaal : Oos-Transvaal, ook kerklik sou deurwerk.

Met die konstituering van die Algemene Kerkvergadering te Rustenburg in Augustus 1853 was die kerkraadslede van Lydenburg nie teenwoordig nie. In die notule van die Volksraadsitting wat in September 1853 plaasgevind het, staan 'Den Ed Volksraad...zijn van gevoelens, als meede den Kerkraad van Lijdenburg, dat onze Kerk op het oogenblik niet meer is verbonden aan de Synode der Kaap....' Lydenburg het homself dus as ' $n$ integrale deel van die Transvaalse kerk beskou en het medeverantwoordelikheid vir die besluit van die eerste Algemene Kerkvergadering aanvaar. Die gesag van die Algemene Kerkvergadering is volledig erken deurdat hulle die tweede vergadering bygewoon het en daaraan deelgeneem het 
(Pont 1965:160). Tog het die regionaal-politieke groep in Oos-Transvaal nie sonder meer die leiding van Wes-Transvaal aanvaar nie.

Tydens sy besoek aan Lydenburg in 1854 kom Van der Hoff te staan voor 'n aanbod van J A Smellekamp, om deur middel van die Amsterdamse geestelike kommissie onder leiding van Jacob Swart, die reiskoste van 'n predikant na Lydenburg te borg. Smellekamp, 'n besoeker by die kerkraadsvergadering, wou hê dat die Algemene Kerkvergadering in Junie 1854 byeen moes kom om oor so'n beroep van 'n tweede predikant, spesifiek vir Lydenburg, te handel.

Van der Hoff het as 'n nuweling in die land, waarskynlik nie besef dat die voorstel maar die punt van 'n ysberg was nie. Die Maritz-Cilliers groep het al vantevore dieselfde soort voorstel tydens die Groot Trek geloods toe hulle nie Erasmus Smit as predikant wou aanvaar nie (Storm 1989b:45). Dit wil voorkom asof Lydenburg klaar besluit het om ds Van der Hoff as 'Wes-Transvaalse' predikant nié te aanvaar nie en dárom hierdie voorstel loods. Van der Hoff trap as ' $t$ ware in die slagyster en kant hom teen hierdie voorstel, hoofsaaklik omdat sy traktementsvoorsiening en reiskoste nog nie finaal gereël was nie. Hy was van mening om 'eerst de eene zaak in orde brengen alvorens die tweede ondernomen werd' (Engelbrecht 1936:100).

Dit loop op 'n rusie uit tussen Van der Hoff en Smellekamp as die kerkraad vir Van der Hoff steun. Smellekamp wend hom na die kommissieraad van Lydenburg wat namens die Volksraad 'n Algemene Kerkvergadering vir Junie belè. So word die tafel gedek vir 'n botsing tussen Smellekamp en Van der Hoff wat op 'n kleinburgerlike vlak verloop. Die uiteinde van die saak is dat die Algemene Kerkvergadering Smellekamp vir ' $n$ jaar onder sensuur plaas. Hy word later deur die landros van Potchefstroom uit die land verban (Engelbrecht 1936:103-104).

Dit is opvallend dat die Lydenburgse afskeiding wat eventueel gevolg het op die kerkraadsvergadering te Lydenburg in 1854, feitlik sonder uitsondering op die rekening van ds Van der Hoff geplaas word met byna 'n uitsondering by Du Plessis (1925:15 vv). Dit was veral Spoelstra (1915) wat die noot hieroor die sterkste ingesit het en daarin nagevolg is (Scholtz 1956:111).

Hierdie botsing tussen twee regionaal-politieke groepe wat uitloop op die stigting van die republiek Lydenburg, word die basis vir die kerklike afskeiding deur ds F L Cachet in 1865-1866 (Engelbrecht 1952a:181 vv).

\section{VAN DER HOFF EN DIE PSALMSINGERS}

Een van die moeilike probleme wat ds Van der Hoff moes hanteer, was die afskeiding in 1859 van 'n betreklik omlynde groep 'Psalmsingers'. Rondom hierdie 
gebeure is daar weinig ooreenstemming wat betref die interpretasie van gebeure. Die primêre feit is dat 'n groep Voortrekkers, hoofsaaklik afkomstig uit Colesberg se wêreld (Spoelstra 1963:63) reeds voor hulle vertrek uit die Kaap besware gehad het oor die sing van Evangeliesche Gezangen in die erediens. Hulle opvatting hieroor is grotendeels bepaal deur die geskrifte van die oude schrijvers; hoofsaaklik uit die kring van die sewentiende-eeuse Nadere Reformasie; wat kerkordelik gesproke vasgehou het aan die opvattings van die Nederlandse Calvinistiese ortodoksie (Pont 1979:69).

Dit is uit hierdie groep dat die versoek om die Gesange in die erediens te laat vaar op die Algemene Kerkvergadering van Augustus 1853 na vore kom (Du Plessis 1925:59). Die vergadering se kompromis-voorstel dat dit almal vrystaan om Gesange te sing of nie, skuif die probleem net vorentoe. Spoelstra (1982:150-170) dui in 'n netjiese artikel aan hoe verwikkeld die Gesangekwessie, die aanvaarding van 'n eie kerkwet en die eerste grondwet van die ZAR in die Transvaalse gemeenskap geword het. Van der Vyver (1858:230 w) trek die kerklike skeuring grotendeels oor die boeg van die 'liberalisme' wat Van der Hoff in die kerk ingedra het en waarvan die Gesange die duidelike simtoom was. Hierdie argument klop egter nie met die feit dat die Psalmberyming van 1775 dieselfde soort opvattings as die Gesange vertoon en nié verset ontlok het nie (Pont 1988:181). Daarby het Engelbreght (1936:153-160) aangetoon dat die leerstellige argument skaars aan die orde was, gesien die wyse waarop Van der Hoff en Postma saam eredienste gehou het en mekaar aanvaar het. Van der Hoff en Postma het mekaar die regterhand gegee, 'de broederhand der gemeenskap, als overeenstemmende in hetzelfde geloof, gemeenschappelijk beleden, en gaf men wederkeerig de verzekering dat het verschil van gevoelen, omtrent het punt der Evangelische Gezangen, geen hinderpaal zou zijn, om elkander als broeders in de bediening te erkennen' (Engelbrecht 1936:158).

Hoewel Van der Hoff die kompromis wat Paul Kruger probeer deurvoer het, gesteun het (Spoelstra 1982:167), is dit duidelik dat dit hier primèr gaan om die vraag na die sing van Gesange al dan nie en nie om 'n leerstellige kwessie nie (Van der Vyver 1958:232 vv). Dit is opvallend dat die afgevaardigdes in 1859, meer nog as Van der Hoff, die noodsaaklikheid van die sing van Gesange beklemtoon en so Postma en sy medestanders voor die keuse stel om die sinodale besluite te eerbiedig of te verwerp (Engelbrecht 1936:156-160).

Die vraag is nié of Van der Hoff kerkskeurend opgetree het nie, maar veel eerder of die afskeiding van Postma regverdigbaar is of nie (Dreyer 1960:87). Dit is opvallend dat hierdie vraag, veral vanuit die kerkordelike hoek, nog maar min aandag geniet het. Die mate waarin die politieke onderstrominge van die dag in die afskeiding 'n rol gespeel het, net soos in die daaropvolgende pogings om die 
skeuring ongedaan te maak (Engelbrecht 1936:160-166), vra ook nog verdere navorsing.

Tog bly dit merkwaardig dat die optrede van Postma om die groep Psalmsingers uit die Nederduitsch Hervormde Kerk te lei, en uit die Vrystaatse en Kaapse Ned Geref Kerke, deur sommige historici (Spoelstra 1982:156, 168; Van der Vyver 1958: $230 \mathrm{vv}$ ) vierkantig op die breë skouers van ds Van der Hoff gepak word. Dit is duidelik dat die Psalmsingers as 'n eie, omlynde groep, ook gedra deur die konventikel-opvattings wat in die Nadere Reformasie-denke so vanselfsprekend was, nooit tevrede sou wees met enige kerklike gemeenskap wat nie ooreengekom het met hulle opvattings nie (Du Plessis 1925:76). Vandaar die hooghartige maar terselfdertyd oppervlakkige veroordeling van die Nederduitsch Hervormde Kerk 'n dekade later, in 1869, toe die Psalmsingers hulle eie skeidingsakte van 1859 weerspreek het (Engelbrecht 1936:169). Op grond van die beskikbare materiaal kan dit gestel word dat die 1859-afskeiding deur die koms van Postma 'n werklikheid geword het en dat dit 'n gebeure was wat ondanks ds Van der Hoff se optrede, in ieder geval sou plaasvind.

\section{KONKLUSIE}

Op grond van die gegewens uit beskikbare en voorhande gepubliseerde materiaal blyk dit dat ds Van der Hoff dikwels verkeerdelik voorgestel word as kerkskeurder, aangesien die vooroordele van die historici meespreek in hulle interpretasie van die historiese materiaal. Dit alles hang waarskynlik saam met die lang stryd wat teen die Nederduitsch Hervormde Kerk gevoer is na die mislukte 'kerkvereniging' van 1885. Dit lyk dus of die werk en persoon van ds Dirk van der Hoff onnodig en onregverdig veroordeel word.

\section{SLOT}

Dit kan nie nagelaat word nie om kortliks te wys op die groot en verdienstelike bydrae wat Dirk van der Hoff gemaak het tot die ordening en bestendiging van die Transvaalse gemeenskap in die jare 1853 tot 1881 . Wanneer hy in Transvaal aankom, word die eerste stappe in die proses van staatvorming geneem. Teen 1881, as Van der Hoff sterf, het die Republiek ontwikkel in 'n geordende staat en volk wat die aanslag van die Engelse in die Vryheidsoorlog kon afslaan. Van der Hoff het in die grotendeels ongeordende Voortrekkergemeenskap waarin hy in 1853 ingetree het, baanbrekers- en beskawingswerk van onskatbare waarde verrig (Pont 1974: 175). 
Dirk van der Hoff was 'n gelowige kerkman, met menslike beperkinge en tekortkominge. Hy het op die fondament van die Voortrekkerkerk voortgebou en in die Transvaal 'n standhoudende kerklike tradisie begin. Die feit dat hy nie alleen predikant was nie, maar ook as opvoeder en gemeenskapsleier moes optree, het sy taak nie vergemaklik nie. Van Warmelo (1881:170), 'n tydgenoot en kollega van ds Van der Hoff, skryf na laasgenoemde se dood soos volg:

Acht-en-twintig jaren en eenige maanden was hij in deze gewesten predikant, eerst van de geheele Transvaal, naderhand, toen er meer hulp kwam, van het district Potchefstroom. Daar is hij aangekomen, daar is hij gestorven, getrouw tot in den dood. Wij willen aan zijne nagedachtenis eene eervolle hulde toebrengen. Bij velen onzer zal hij in levendig aandenken blijven; hij is den weg van alle vleesch gegaan, maar heeft niet te vergeefs geleefd, en terwijl hij het loon der getrouwe diensknechten van den Heer heeft ontvangen, zullen wij hem als onzen voorganger gedenken, ziende de uitkomst zijner wandeling....Als mensch, in den dagelijkschen omgang, had hij zijne gebreken. Hij was kort gebonden, een kwaal die met de jaren niet verminderde. Maar, zooals bijna algemeen gezegd werd, hij mocht een foutje maken; het werd hem vergeven, hij is onze oudste en eerste leeraar.

\section{Literatuurverwysings}

Beyers, C 1967. Die Kaapse patriotte gedurende die laaste kwart van die agtiende eeu en die voortlewing van hulle denkbeelde. Pretoria: Van Schaik.

Dreyer, J G M [1960]. Afskeiding prinsipieel benader. HTS 16/2, 76-88.

Du Plessis, J 1925. De Gereformeerde Kerk in wording en werking. Paarl: Paarlse Drukpers.

Duvenage, G D J 1966. Die republiek Lydenburg in Suid-Afrika: Agtergrond, ontstaan en einde. Ongepubliseerde proefskrif, Universiteit van Suid-Afrika, Pretoria.

Engelbrecht, S P 1936. Geskiedenis van die Nederduits Hervormde Kerk van Afrika. Pretoria: De Bussy.

--- [1952a]. Ds Frans Lion Cachet. HTS 9/3, 181-230.

-.- [1952b]. Ds Dirk van der Hoff en die Voortrekker-ideaal. HTS 9/3, 130-163. 
Erasmus, F W L 1950. Ds Dirk van der Hoff, 'n kritiese beoordeling van sy werksaamhede in die Zuid-Afrikaanse Republiek. Ongepubliseerde MA verhandeling, Potchefstroomse Universiteit vir Christelike Hoër Onderwys.

Jooste, J P 1846. Die verhouding tussen kerk en staat aan die Kaap tot die helfte van die negentiende eeu. Bloemfontein: Sacum.

--- 1871. Open brief aan ds $D$ van der Hoff.

Nederduitsch Hervormde Kerk van Afrika. Notule van die Algemene Kerkvergadering 1853-1874, Deel 1.

Oberholzer, J P 1989. Die Voortrekkerideaal: Natal of Transvaal? HTS 45/3, 598609.

Pelzer, A N 1950. Geskiedenis van die Suid-Afrikaanse Republiek, deel 1. Kaapstad: Balkema.

Ploeger, J [1952]. Prof Ulrich Gerhard Lauts. HTS 9/3, 100-129.

Pont, A D s a. Die Herderlijken brief van die sinode van 1837. HTS 34/4, 91-105.

--- [1965]. Die vestiging van die Nederduitsch Hervormde Kerk in 1853 en die eerste afskeiding van Lydenburg in 1854: Kerkregtelike implikasies. HTS 20/3, 149-161.

--- [1974]. Rondom die figuur van ds Dirk van der Hoff. HTS 30/3 \& 4, 163-182.

--- 1979. Die Psalmzingers, in Loader, J A (red), 'n Nuwe lied vir die Here. Pretoria: HAUM.

-.- 1986. Die Voortrekkerkerk 1836-1852. Ongepubliseerde lesingaantekeninge, Universiteit van Pretoria.

--- 1988. Algemene Kerkgeskiedenis: 'n Inleiding tot die Nederlandse Kerkgeskiedenis - van die beginjare tot 1795 . Ongepubliseerde lesingaantekeninge, Universiteit van Pretoria.

--- 1989. Die Groot Trek en die Kerk. HTS 45, 655-669.

Scholtz, G D 1956. Die geskiedenis van die Nederduits Hervormde of Gerefor-meerde Kerk 1842-1885. Kaapstad: NG Kerkboekhandel.

Smellekamp, JA 1854. Mijn wedenaren in de Zuid-Afrikaansche Republiek vooral in betrekking met den Predikant $D$ van der Hoff. Kaapstad.

Spoelstra, B 1982. Paul Kruger as lid van die Nederduitsch Hervormde kerk, 18531859. Die kerk in die wêreld. Pretoria: HAUM.

Spoelstra, C 1915. Het kerkelijk en godsdienstig leven der Boeren na den Grooten Trek. Kampen: Kok.

--- 1963. Die Doppers in Suid-Afrika 1760-1899. Kaapstad: Nasionale Boekhandel.

Storm, J M G 1989a. Die konvensie van Sandrivier as die afsluiting van die Groot Trek. HTS 45, 680-694. 
--- 1989b. Die Voortrekkerkerk 1836-1853. Pretoria: Kital.

Van der Vyver, G C P 1958. Professor Dirk Postma 1818-1890. Potchefstroom: Pro Rege.

Van der Watt, P B 1977. Die Nederduitse Gereformeerde Kerk 1834-1866. Pretoria: NG Kerkboekhandel.

Van Warmelo, N J 1881. Een herinnering aan ds Dirk van der Hoff. HTS 9/3. 170176. 